\title{
Genuine genetic redundancy in maleylacetate- reductase-encoding genes involved in degradation of haloaromatic compounds by Cupriavidus necator JMP134
}

\author{
Danilo Pérez-Pantoja, ${ }^{1}$ Raúl A. Donoso, ${ }^{2}$ Miguel A. Sánchez ${ }^{1}$ \\ and Bernardo González ${ }^{1,2}$
}

Correspondence

Bernardo González

bernardo.gonzalez@uai.cl
Received 24 June 2009

Accepted 10 August 2009

\author{
${ }^{1}$ Departamento de Genética Molecular y Microbiología, Facultad de Ciencias Biológicas, P. \\ Universidad Católica de Chile, Millennium Nucleus on Microbial Ecology and Environmental \\ Microbiology and Biotechnology, NM-EMBA, Center for Advanced Studies in Ecology and \\ Biodiversity, CASEB, Santiago, Chile \\ ${ }^{2}$ Facultad de Ingeniería y Ciencia, Universidad Adolfo Ibáñez, Santiago, Chile
}

\section{INTRODUCTION}

Maleylacetate reductases (MAR) play an important role in degradation of (halo)aromatic compounds in fungi (Gaal \& Neujahr, 1980; Jones et al., 1995; Patel et al., 1992; Sparnins et al., 1979), Actinobacteria (Huang et al., 2006; Perry \& Zylstra, 2007; Seibert et al., 1998; Travkin et al., 1999) and Proteobacteria (Armengaud et al., 1999; Daubaras et al., 1996; Endo et al., 2005; Moonen et al., 2008; Nikodem et al., 2003; Seibert et al., 2004; Yoshida et al., 2007). In these micro-organisms, maleylacetate (MA) or 2-chloromaleylacetate (2-CMA) are generated during turnover of halocatechols, hydroxyquinol, chlorohydrox-

Abbreviations: 2-CMA, 2-chloromaleylacetate; 2,4-D, 2,4-dichlorophenoxyacetate; 2,4,6-TCP, 2,4,6-trichlorophenol; 3-CB, 3-chlorobenzoate; 4-FB, 4-fluorobenzoate; MA, maleylacetate; MAR, maleylacetate reductase(s). yquinol, hydroquinone and chlorohydroquinone, as ringcleavage intermediates of a broad array of metabolized compounds.

MA is transformed to 3-oxoadipate through an NAD(P)Hdependent reduction of the carbon-carbon double bond catalysed by MAR (Fig. 1a). In the case of 2-CMA, MAR initially catalyses the $\mathrm{NAD}(\mathrm{P}) \mathrm{H}$-dependent dechlorination to MA, which is then reduced to 3-oxoadipate (Fig. 1a). Therefore, 2 moles of $\mathrm{NAD}(\mathrm{P}) \mathrm{H}$ per mole of substrate are consumed during the MAR-mediated conversion of 2CMA to 3-oxoadipate, which is subsequently funnelled to the Krebs cycle (Kaschabek \& Reineke, 1992, 1995; Vollmer et al., 1993).

Cupriavidus necator JMP134 is a betaproteobacterium able to grow on a wide range of aromatic and haloaromatic compounds as sole carbon and energy source 
(a)

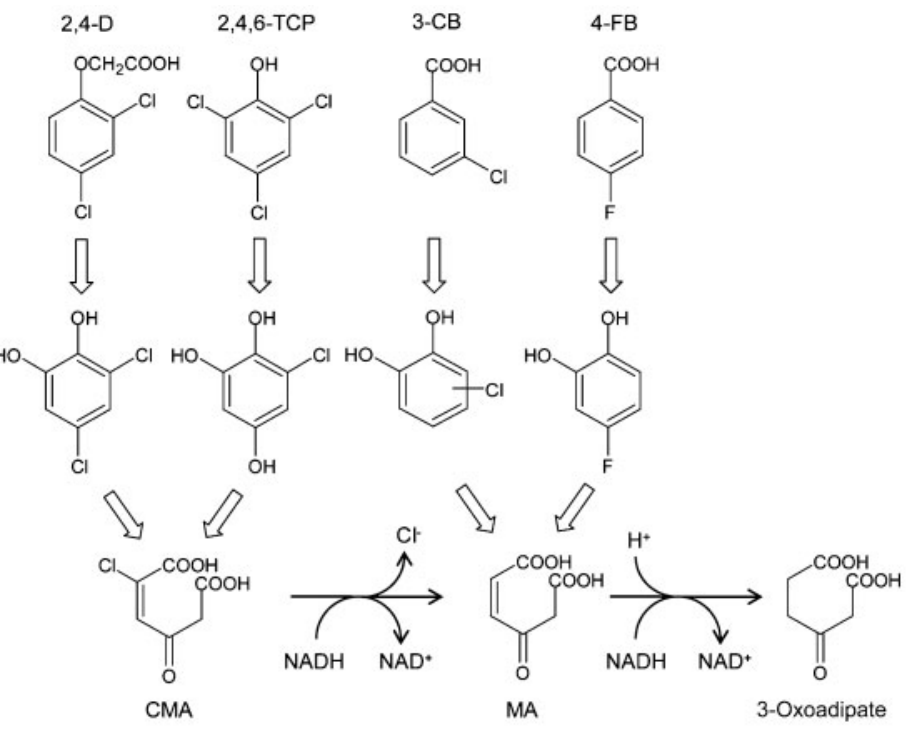

(b)

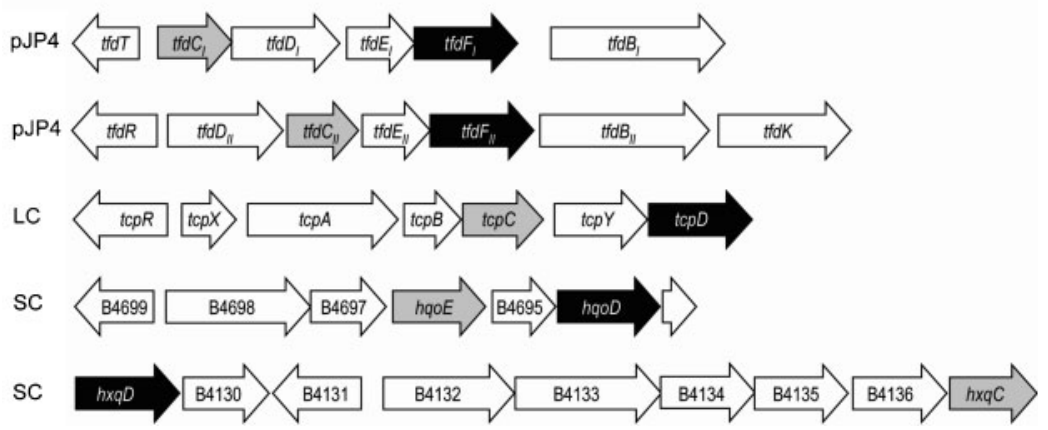

Fig. 1. (a) Haloaromatic compounds channelled to MA in C. necator JMP134 and reactions catalysed by MAR. (b) Organization of gene clusters in C. necator JMP134 comprising MAR-encoding genes (black arrows). Ring-cleavage dioxygenase-encoding genes are shown as grey arrows. LC, Large chromosome; SC, small chromosome.
(Pérez-Pantoja et al., 2008). The haloaromatic compounds catabolized by $C$. necator JMP134 include 2,4-dichlorophenoxyacetate (2,4-D), 3-chlorobenzoate (3-CB), 2,4,6trichlorophenol (2,4,6-TCP) and 4-fluorobenzoate (4-FB) which, through diverse catabolic steps, are converted to MA or 2-CMA (Fig. 1a) (Pérez-Pantoja et al., 2008).

The role of MAR in C. necator JMP134 has been well established in the turnover of 3,5-dichlorocatechol, 3- (and 4-) chlorocatechol, 4-fluorocatechol and 6-chlorohydroxyquinol, generated during mineralization of 2,4-D (Seibert et al., 1993; Vollmer et al., 1993), 3-CB (Laemmli et al., 2000; Pérez-Pantoja et al., 2000), 4-FB (Schlomann et al., 1990a) and 2,4,6-TCP (Padilla et al., 2000; Sánchez \& González, 2007), respectively. Two MAR-encoding genes $t f d F_{I}$ and $t f d F_{I I}$ - have been identified in $C$. necator JMP134, both belonging to specialized gene clusters for chlorocatechol turnover located on the pJP4 catabolic plasmid (Fig. 1b) (Trefault et al., 2004). The functionality of both genes and their expression during mineralization of 2,4-D and 3-CB has been confirmed (Kasberg et al., 1995; Laemmli et al., 2000, 2004; Pérez-Pantoja et al., 2000; Plumeier et al., 2002). Additionally, the presence of at least one chromosomally encoded MAR has been shown (Padilla et al., 2000; Pérez-Pantoja et al., 2000; Plumeier et al., 2002; Vollmer et al., 1993). Recently, the analysis of the C. necator JMP134 genome sequence has revealed the presence of three hypothetical MAR-encoding genes located in chromosomal replicons (Fig. 1b). These additional gene sequences have been termed tcpD (Sánchez \& González, 2007), hqoD and $h x q D$, since they are clustered with genes putatively encoding 2,4,6-TCP, hydroquinone and hydroxyquinol-metabolizing oxygenases, respectively (Pérez-Pantoja et al., 2008); however, their possible function requires experimental confirmation.

In this work, the functionality of the chromosomal MARencoding genes of C. necator JMP134 was assessed. The results reveal a genuine genetic redundancy for MAR functions in the catabolism of haloaromatic compounds.

\section{METHODS}

Bacterial strains, plasmids and growth conditions. Bacterial strains and plasmids used in this study are listed in Table 1. C. necator JMP134(pJP4) and its derivatives were grown at $30{ }^{\circ} \mathrm{C}$ in mineral salts medium using $50 \mathrm{mM}$ phosphate buffer (pH 7.5) (Dorn et al., 1974). The medium was supplemented with different haloaromatic compounds - 2,4-D (2.5 mM), 3-CB (2.5 mM), 4-FB (2.5 mM) and 2,4,6-TCP $(0.5 \mathrm{mM})$ - or fructose $(10-20 \mathrm{mM})$ as sole carbon source, 
Table 1. Bacterial strains and plasmids used in this work

\begin{tabular}{|c|c|c|}
\hline Strain or plasmid & Relevant phenotype and/or genotype ${ }^{\star}$ & Source or reference $\dagger$ \\
\hline \multicolumn{3}{|l|}{ C. necator strains } \\
\hline JMP134(pJP4) & $2,4-\mathrm{D}^{+} 3-\mathrm{CB}^{+} 4-\mathrm{FB}^{+} 2,4,6-\mathrm{TCP}^{+}, \mathrm{Hg}^{\mathrm{R}}$ & DSMZ Culture Collection \\
\hline $\mathrm{JMP} 134\left(\mathrm{pJP} 4 \Delta t f d F_{\mathrm{II}}\right)$ & $t f d F_{\mathrm{II}}$ mutant & This study \\
\hline $\mathrm{JMP} 134 \Delta t c p D(\mathrm{pJP} 4)$ & $t c p D$ mutant, $\mathrm{Km}^{\mathrm{R}}$ & This study \\
\hline JMP134 4 hooD(pJP4) & hqoD mutant, $\mathrm{Km}^{\mathrm{R}}$ & This study \\
\hline $\mathrm{JMP} 134\left(\mathrm{pJP} 4 \Delta t f d F_{\mathrm{I}} \Delta t f d F_{\mathrm{II}}\right)$ & $t f d F_{\mathrm{I}}$ and $t f d F_{\mathrm{II}}$ mutant, $\mathrm{Gm}^{\mathrm{R}}$ & This study \\
\hline $\mathrm{JMP} 134 \Delta t c p D\left(\mathrm{pJP} 4 \Delta t f d F_{\mathrm{I}} \Delta t f d F_{\mathrm{II}}\right)$ & $t c p D t f d F_{\mathrm{I}}$ and $t f d F_{\mathrm{II}}$ mutant, $\mathrm{Km}^{\mathrm{R}} \mathrm{Gm}^{\mathrm{R}}$ & This study \\
\hline $\mathrm{JMP} 134 \Delta h q o D\left(\mathrm{pJP} 4 \Delta t f d F_{\mathrm{I}} \Delta t f d F_{\mathrm{II}}\right)$ & $h q o D$ tfdF and $t f d F_{\mathrm{II}}$ mutant, $\mathrm{Km}^{\mathrm{R}} \mathrm{Gm}^{\mathrm{R}}$ & This study \\
\hline $\mathrm{JMP} 134 \Delta h x q D\left(\mathrm{pJP} 4 \Delta t f d F_{\mathrm{I}} \Delta t f d F_{\mathrm{II}}\right)$ & $h x q D t f d F_{\mathrm{I}}$ and $t f d F_{\mathrm{II}}$ mutant, $\mathrm{Km}^{\mathrm{R}} \mathrm{Gm}^{\mathrm{R}}$ & This study \\
\hline \multicolumn{3}{|l|}{ Other strains } \\
\hline B. phytofirmans PsJN & $2,4-\mathrm{D}^{-}$ & Sessitsch et al. (2005) \\
\hline pKD4 & $\operatorname{oriR}[\mathrm{R} 6 \mathrm{~K} \gamma], \mathrm{Ap}^{\mathrm{R}} \mathrm{Km}^{\mathrm{R}}$ & Datsenko \& Wanner (2000) \\
\hline pKD46 & $\operatorname{araC}-P_{a r a B^{-}} \lambda$ Red recombination genes $(\gamma-\beta$-exo $), \mathrm{Ap}^{\mathrm{R}}$ & Datsenko \& Wanner (2000) \\
\hline pBH474 & BHR, Flp recombinase expressed constitutively, $\mathrm{Gm}^{\mathrm{R}} \mathrm{Suc}^{\mathrm{S}}$ & House et al. (2004) \\
\hline pBS1 & $\mathrm{BHR}, \operatorname{araC}-P_{\mathrm{BAD}}, \mathrm{Gm}^{\mathrm{R}}$ & Bronstein et al. (2005) \\
\hline pBS1tcpD & $t c p D$-expressing pBS1 derivative, $\mathrm{Gm}^{\mathrm{R}}$ & This study \\
\hline pBS1hqoD & hqoD-expressing pBS1 derivative, $\mathrm{Gm}^{\mathrm{R}}$ & This study \\
\hline pBS1hxqD & $h x q D$-expressing pBS1 derivative, $\mathrm{Gm}^{\mathrm{R}}$ & This study \\
\hline pCR2.1-TOPO & Suicide vector in C. necator $\mathrm{JMP} 134, \mathrm{Ap}^{\mathrm{R}} \mathrm{Km}^{\mathrm{R}}$ & Invitrogen Life Technologies \\
\hline pTOPO $\Delta t c p D$ & pCR2.1 derivative with internal fragment of $t c p D, A p^{\mathrm{R}} \mathrm{Km}^{\mathrm{R}}$ & This study \\
\hline pTOPO $\Delta h q o D$ & pCR2.1 derivative with internal fragment of $h q o D, \mathrm{Ap}^{\mathrm{R}} \mathrm{Km}^{\mathrm{R}}$ & This study \\
\hline pTOPO $\Delta h x q D$ & pCR2.1 derivative with internal fragment of $h x q D, \mathrm{Ap}^{\mathrm{R}} \mathrm{Km}^{\mathrm{R}}$ & This study \\
\hline
\end{tabular}

${ }^{\star} A p^{R}$, ampicillin resistance; $\mathrm{Gm}^{\mathrm{R}}$, gentamicin resistance; $\mathrm{Km}^{\mathrm{R}}$, kanamycin resistance; $\mathrm{Rf}^{\mathrm{R}}$, rifampicin resistance; $\mathrm{Hg}^{\mathrm{R}}$, mercury resistance; Suc , sucrose sensitivity; BHR, broad host range.

$†$ DSMZ, Deutsche Sammlung von Mikroorganismen und Zellkulturen GmbH, Braunschweig, Germany.

plus the appropriate antibiotics: kanamycin $\left(100 \mu \mathrm{g} \mathrm{ml}{ }^{-1}\right)$ and/or gentamicin $\left(20 \mu \mathrm{g} \mathrm{ml}^{-1}\right)$ (Table 1). Burkholderia phytofirmans PsJN(pJP4) and its derivatives were grown under the same conditions but with 2,4-D $(2.5 \mathrm{mM})$ as growth compound plus gentamicin $\left(20 \mu \mathrm{g} \mathrm{ml}^{-1}\right)$ and L-arabinose $(0.25 \mathrm{mM})$ as inducer of the $\mathrm{P}_{\mathrm{BAD}}$ promoter in pBS1 derivatives (Table 1). Pseudomonas putida KT2442 and its derivatives were grown under the same conditions but with succinate $(30 \mathrm{mM})$ plus gentamicin $\left(20 \mu \mathrm{g} \mathrm{ml}^{-1}\right)$ and L-arabinose (5 mM) (Table 1). Escherichia coli Mach 1 (Invitrogen Life Technologies) was used routinely as plasmid host and was grown at $37^{\circ} \mathrm{C}$ in Luria-Bertani (LB) medium plus the appropriate antibiotic: ampicillin $\left(100 \mu \mathrm{g} \mathrm{ml}^{-1}\right)$, kanamycin $\left(100 \mu \mathrm{g} \mathrm{ml}^{-1}\right)$ or gentamicin $\left(20 \mu \mathrm{g} \mathrm{ml}^{-1}\right)$. Growth was determined by measuring the optical density at $600 \mathrm{~nm}$. At least two replicates were performed for each growth measurement.

Detection of transcripts by RT-PCR. Cells of C. necator JMP134 were grown overnight in minimal medium with $10 \mathrm{mM}$ fructose as carbon source. This culture was used to inoculate fresh medium and grown until $\mathrm{OD}_{600}=0.7$, subsequently supplemented with $0.25 \mathrm{mM}$ 3-CB, 2,4-D, 4-FB or 2,4,6-TCP and incubated for $1 \mathrm{~h}$. Then, total RNA was obtained from $4 \mathrm{ml}$ of the culture, using RNAprotect Bacteria Reagent and RNeasy Mini kit (Qiagen), according to manufacturer's instructions. The obtained RNA was quantified using a GeneQuant 1300 Spectrophotometer (GE Healthcare) and treated with the Turbo DNase kit (Ambion) to remove any DNA contamination, following the manufacturer's instructions. RT-PCR was carried out using the ImProm-II Reverse Transcription System (Promega) with $1 \mu \mathrm{g}$ total RNA in $20 \mu \mathrm{l}$ reactions. After reverse transcription, PCR amplifications were carried out using the primer pairs $t f d F_{\mathrm{I}} \mathrm{intFW} / t f d F_{\mathrm{I}} \mathrm{intRV}, t f d F_{\mathrm{II}}$ intFW/ $t f d F_{\mathrm{II}} \mathrm{intRV}$, $t c p D$ intFW2/ tcpDintRV2, hqoDintFW/hqoDintRV and hxqDintFW/hxqDintRV (these and all primer pairs used in this work are shown in Table 2) in a $25 \mu \mathrm{l}$ mixture which contained $1 \mu \mathrm{l}$ total cDNA, 50 pmol each primer, $50 \mu \mathrm{M}$ each dNTP, $1 \mathrm{mM} \mathrm{MgCl}_{2}$ and $5 \mathrm{U}$ Taq DNA polymerase, prepared in the reaction buffer supplied by the manufacturer. The temperature programme was as follows: initial denaturation at $95{ }^{\circ} \mathrm{C}$ for $5 \mathrm{~min}$, then 28 cycles of $30 \mathrm{~s}$ at $95{ }^{\circ} \mathrm{C}, 30 \mathrm{~s}$ at $60{ }^{\circ} \mathrm{C}$ and $60 \mathrm{~s}$ at $72{ }^{\circ} \mathrm{C}$, with a final extension at $72{ }^{\circ} \mathrm{C}$ for $10 \mathrm{~min}$. Negative control reactions were performed in the same way, except that reverse transcriptase was omitted in the reaction mixtures.

Construction of plasmid derivatives expressing MAR-encoding genes. $t c p D$, $h q o D$ and $h x q D$ were PCR-amplified from DNA obtained from strain JMP134, using primer pairs $t c p D F W / t c p D R V$, $h q o D F W / h q o D R V$ and $h x q D F W / h x q D R V$, respectively. The PCR products were cloned individually using the pCR8/GW/TOPO TA Cloning kit (Invitrogen Life Technologies), and the resulting plasmids 
Table 2. Primer pairs used in this work

\begin{tabular}{|c|c|}
\hline Primer & Sequence $\left(5^{\prime} \rightarrow 3^{\prime}\right)^{*}$ \\
\hline \multicolumn{2}{|c|}{ RT-PCR analysis and inactivation of chromosomal MAR genes } \\
\hline$t f d F_{\mathrm{I}}$ intFW & ACGCGAGTTAGCGAAGGATA \\
\hline$t f d F_{\mathrm{I}}$ intRV & GAGATAGCAAGCGGCAAATC \\
\hline$t f d F_{I I}$ intFW & CTCTACGACCCGCATCACCT \\
\hline$t f d F_{I I}$ intRV & GAGCAGATGGCAGAGCTTGT \\
\hline tcpDintFW 1 & GGCTCGGAGATGACTACGAT \\
\hline tcpDintRV1 & CATGGGCGTACAAACCTTCT \\
\hline tcpDintFW2 & CACGCAGCAGAAGGTTTGTA \\
\hline tcpDintRV2 & AGGATGATCGTGTGCGTTTC \\
\hline hqoDintFW & GGTCTACGATCCCGAACTGA \\
\hline hqoDintRV & GTATGGCACAGCTTGTGGTG \\
\hline$h x q D$ intFW & ATCTACGATCCCGCACTGAG \\
\hline$h x q D$ intRV & ATGGCACAGCTTGTGATGAA \\
\hline \multicolumn{2}{|c|}{ Inactivation of MAR genes encoded in pJP4 } \\
\hline MUTtfdF $\mathrm{I} F W$ & GACCCTTCATGAAGAAGTTCACGCTTGACTACCTGAGCCCGTGTAGGCTGGAGCTGCTTC \\
\hline MUTtfdF $\mathrm{RV}$ & GCGGAGTTGCAGGTCACATTATTTGAAATCCGGTCTTCGCCATTCCGGGGATCCGTCGACC \\
\hline MUTtfdF $\mathrm{II} F W$ & CCGGCGATCTGAATGAATTCGTTGCGCACTTCTGGCCGGTGTGTAGGCTGGAGCTGCTTC \\
\hline MUTtfdF $\mathrm{IIV}$ & AGAGGTCCATGGGATGTCCGGTTCACGCCGGCATTTCTCCATTCCGGGGATCCGTCGACC \\
\hline \multicolumn{2}{|c|}{ Cloning of MAR genes and verification of gene disruption } \\
\hline$t f d F_{\mathrm{I}} \mathrm{FW}$ & CTCGAACTGCTTGCAATGTT \\
\hline$t f d F_{\mathrm{I}} \mathrm{RV}$ & ACCGTACTAAACGCGGAGTG \\
\hline$t f d F_{\mathrm{II}} \mathrm{FW}$ & ATCTCGAATCGCCGGACA \\
\hline$t f d F_{I I} R V$ & TCCTTATCGATAGGTCGGGTCG \\
\hline$t c p D F W$ & TATCGTTTTGACGGGAGACC \\
\hline$t c p D \mathrm{RV}$ & CCAACACATACCGCTTCAAA \\
\hline hqoDFW & GAGCAAAACCATGAAATCG \\
\hline hqoDRV & CGATGTCATAGGCGACGA \\
\hline$h x q D F W$ & GACTGAAACGGGAGTTGTCC \\
\hline$h x q D R V$ & TGGTGACTCCTTTCCTCCTG \\
\hline
\end{tabular}

*The 20 bp priming sequences for pKD4 (Table 1) are underlined.

were electroporated into competent cells of E. coli Mach 1. Then, MAR genes were transferred from pCR8/GW/TOPO derivatives to the pBS1 vector (Bronstein et al., 2005) by recombination-based transfer of the PCR product using the Gateway LR Clonase II Enzyme Mix (Invitrogen Life Technologies), according to the manufacturer's instructions. The identity of MAR genes in the recombinant plasmids was confirmed by sequencing. The generated recombinant plasmids were electroporated into P. putida KT2442.

Preparation of cell extracts. $P$. putida KT2442 derivatives harbouring MAR genes were grown to late exponential phase in mineral medium with succinate $(30 \mathrm{mM})$ as sole carbon source and in the presence of $5 \mathrm{mM}$ L-arabinose. Mutant derivatives of C. necator JMP134 were grown for $18 \mathrm{~h}$ in mineral medium with fructose $(20 \mathrm{mM})$ in the presence of $2,4-\mathrm{D}(2 \mathrm{mM})$ or $2,4,6-\mathrm{TCP}(0.5 \mathrm{mM})$ as inducers of MAR activity. P. putida and C. necator cells were harvested, centrifuged at 8500 r.p.m. for $10 \mathrm{~min}$ and washed twice with 1 vol. Tris/acetate ( $50 \mathrm{mM}, \mathrm{pH} 7.5)$. Then, the cells were resuspended in $1 \mathrm{ml}$ Tris/acetate $(50 \mathrm{mM}, \mathrm{pH} 7.5)$ and subjected to lysis by sonication with three pulses of $10 \mathrm{~s}$ at potency level $15 \mathrm{using}$ an ultrasonic cell disruptor (Microson XL2000; Misonic Inc). The lysates were subjected to two successive centrifugations at 16000 r.p.m. for $45 \mathrm{~min}$ at $4{ }^{\circ} \mathrm{C}$. Finally, supernatants were collected and used for enzyme assays.

MAR activity assays. MAR activity was measured spectrophotometrically by the decrease of cofactor NADH at $340 \mathrm{~nm}$ $\left(\varepsilon_{340}=6300 \mathrm{M}^{-1} \mathrm{~cm}^{-1}\right)$. The standard assay mixture contained $\left(\mathrm{ml}^{-1}\right) 35 \mathrm{mM}$ Tris/acetate buffer ( $\left.\mathrm{pH} 7.5\right), 100 \mu \mathrm{M} \mathrm{MA}, 0.2 \mathrm{mM}$ $\mathrm{NADH}$ and a suitable quantity of cell extract. After non-specific (in the absence of MA) NADH oxidation at $340 \mathrm{~nm}$ had been recorded for $2 \mathrm{~min}$, MA was added and recording of NADH oxidation was continued for $2 \mathrm{~min}$. MAR activity was calculated from the difference between the non-specific and MA-dependent oxidation rates. The protein concentration in the cell extracts was estimated as described by Bradford (1976). BSA was used as protein standard.

Inactivation of $\boldsymbol{t} \boldsymbol{f d} \boldsymbol{F}_{\mathbf{I}}$ and $\boldsymbol{t} \boldsymbol{f} \boldsymbol{d} \boldsymbol{F}_{\mathbf{I I}}$ in $\mathbf{p J P 4} . t f d F_{\mathrm{I}}$ and $t f d F_{\mathrm{II}}$ were independently inactivated in E. coli strain BW25113, harbouring pJP4, using a procedure described by Datsenko \& Wanner (2000). Primer pairs MUTtfdF $F_{\mathrm{I}} \mathrm{FW} / \mathrm{MUT} t f d F_{\mathrm{I}} \mathrm{RV}$ (for $t f d F_{\mathrm{I}}$ ) and $\mathrm{MUT} t f d F_{\mathrm{II}} \mathrm{FW} /$ MUT $t f d F_{I I} R V$ (for $t f d F_{I I}$ ), which contain $20 \mathrm{bp}$ priming sequences for pKD4 (Table 1) and $40 \mathrm{bp}$ homology extensions of the $t f d F_{\mathrm{I}}$ or $t f d F_{\text {II }}$ gene sequences, were synthesized. These primer pairs were used with pKD4 as a template to amplify the kanamycin resistance gene flanked by $40 \mathrm{bp}$ of the $t f d F_{\mathrm{I}}$ or $t f d F_{\text {II }}$ gene sequences. The following PCR program was used: $95{ }^{\circ} \mathrm{C}$ for 5 min, 28 cycles of $95{ }^{\circ} \mathrm{C}$ for $30 \mathrm{~s}$, $60{ }^{\circ} \mathrm{C}$ for $30 \mathrm{~s}$ and $72{ }^{\circ} \mathrm{C}$ for $90 \mathrm{~s}$, and then $72{ }^{\circ} \mathrm{C}$ for $10 \mathrm{~min}$. The PCR products were used to inactivate $t f d F_{\mathrm{I}}$ or $t f d F_{\mathrm{II}}$ in $E$. coli strain BW25113(pJP4), harbouring pKD46 that provides the $\lambda$ Red recombination system from the arabinose-inducible $\mathrm{P}_{\mathrm{BAD}}$ promoter, by a previously adapted procedure (Pérez-Pantoja et al., 2003). The pJP4 derivatives containing an inactivated $t f d F_{\text {I }}$ or $t f d F_{\text {II }}$ gene were 
then transferred to strain JMP134 by biparental conjugation as described by Clément et al. (2000), and the transconjugants were selected on minimal medium agar plates supplemented with $3 \mathrm{mM}$ benzoate plus kanamycin $\left(100 \mu \mathrm{g} \mathrm{ml}^{-1}\right)$. The transconjugant colonies were propagated in liquid cultures with kanamycin by five successive transfers until the native wild-type pJP4 plasmid was completely removed and only the corresponding pJP4 derivative containing an inactivated version of $t f d F_{\mathrm{I}}$ or $t f d F_{\mathrm{II}}$ was present in C. necator JMP134. Primer pairs $t f d F_{\mathrm{I}} \mathrm{FW} / t f d F_{\mathrm{I}} \mathrm{RV}$ and $t f d F_{\mathrm{II}} \mathrm{FW} / t f d F_{\mathrm{II}} \mathrm{RV}$ were used to verify by PCR the correct insertion by recombination of the kanamycin resistance cassette in place of the $t f d F_{I}$ or $t f d F_{\text {II }}$ gene sequences. Second, the inserted kanamycin cassettes were eliminated by electroporating a helper plasmid, pBH474 (House et al., 2004), expressing Flp recombinase (Datsenko \& Wanner, 2000), generating the respective kanamycin resistance-free mutant strains. Finally, these kanamycinsensitive mutant derivatives were streaked on $5 \%$ sucrose LB agar plates to select for the loss of pBH474, and the deletions in $t f d F_{\mathrm{I}}$ or $t f d F_{\mathrm{II}}$ were verified by PCR using the primer pairs $t f d F_{\mathrm{I}} \mathrm{FW} / t f d F_{\mathrm{I}} \mathrm{RV}$ and $t f d F_{\mathrm{II}} \mathrm{FW} / t f d F_{\mathrm{II}} \mathrm{RV}$, to obtain C. necator JMP134(pJP4 $\left.\Delta t f d F_{\mathrm{I}}\right)$ and $C$. necator JMP134(pJP4 $\Delta t f d F_{\text {II }}$ ), respectively (Table 1).

A double $\Delta t f d F_{\mathrm{I}} \Delta t f d F_{\text {II }}$ mutant derivative of $C$. necator JMP134 was generated from strain JMP134 $\left(\mathrm{pJP} 4 \Delta t f d F_{\mathrm{I}}\right)$ by electroporating the suicide pLitmus $\Delta t f d F_{\text {II }}$ plasmid (Table 1), containing a $t f d F_{\text {II }}$ gene sequence disrupted with the insertion of a gentamicin resistance cassette. Mutant derivatives subjected to a double homologous recombination event between $t f d F_{\text {II }}$ alleles of pJP4 $\Delta t f d F_{\text {I }}$ and pLitmus $\Delta t f d F_{\text {II }}$ were selected on the basis of a gentamicin-resistant and ampicillin-sensitive phenotype. The correct insertion of the gentamicin resistance cassette in $t f d F_{\text {II }}$ was verified by PCR using primer pair $t f d F_{\text {II }} \mathrm{FW} / t f d F_{\text {II }} \mathrm{RV}$ to obtain strain JMP134(pJP4 $\left.\Delta t f d F_{\mathrm{I}} \Delta t f d F_{\text {II }}\right)$ (Table 1).

\section{Chromosomal disruption of gene sequences in C. necator} JMP134. An internal fragment of each MAR gene was individually amplified by PCR from strain JMP134 DNA, using the primer pairs tcpDintFW1/tcpDintRV1, hqoDintFW/hqoDintRV and hxqDintFW/ $h x q D$ intRV. The PCR products were cloned individually using the pCR2.1-TOPO system (Invitrogen Life Technologies) to generate recombinant plasmids pTOPO $\Delta t c p D, \quad$ pTOPO $\Delta h q o D$ and pTOPO $\Delta h x q D$ (Table 1$)$. These suicide plasmids were independently electroporated into cells of C. necator JMP134 to obtain a onerecombination-event disruption of the target chromosomal gene. Mutant derivatives were selected on LB agar containing kanamycin, and correct recombinational insertion in the corresponding target gene was confirmed by PCR using primer pairs $t c p D F W / t c p D R V$, hqoDFW/ $h q o D R V$ and $h x q D F W / h x q D R V$, to obtain derivatives JMP134 $\Delta t c p D$, JMP134 $h q o D$ and JMP134 $h x q D$, respectively (Table 1 ).

Triple MAR-encoding gene mutant derivatives of C. necator JMP134 were constructed by mobilizing the pJP $4 \Delta t f d F_{\mathrm{I}} \Delta t f d F_{\mathrm{II}}$ plasmid by biparental conjugation from strain JMP134(pJP4 $\left.\Delta t f d F_{\mathrm{I}} \Delta t f d F_{\mathrm{II}}\right)$ to each chromosomally encoded MAR mutant derivative, and subsequent selection of transconjugants on minimal medium agar plates supplemented with $3 \mathrm{mM}$ benzoate plus kanamycin $\left(100 \mu \mathrm{g} \mathrm{m}{ }^{-1}\right)$ and gentamicin $\left(20 \mu \mathrm{g} \mathrm{ml}^{-1}\right)$. The transconjugant colonies were propagated in liquid cultures with gentamicin and kanamycin by five successive transfers until the native wild-type pJP4 plasmid of each chromosomally encoded MAR mutant was completely removed, and only the pJP $4 \Delta t f d F_{\mathrm{I}} \Delta t f d F_{\mathrm{II}}$ derivative was present (checked by PCR). The simultaneous inactivation of three MAR-encoding genes in each triple mutant derivative was verified by PCR using the appropriate primer pairs.

Chemicals. 2,4-D, 3-CB, 4-FB and 2,4,6-TCP were purchased from Sigma-Aldrich. MA was prepared by alkaline hydrolysis from cisdienelactone, which was kindly provided by Walter Reineke
(Bergische Universität-Gesamthochschule Wuppertal, Germany). All MA solutions were used on the same day that they were prepared.

\section{RESULTS}

\section{RT-PCR analysis of MAR-encoding genes in C. necator JMP134}

In order to elucidate the role of MAR-encoding genes in $C$. necator JMP134, an RT-PCR analysis of gene expression in cells exposed to haloaromatic compounds channelled to MA was initially performed. C. necator JMP134 was exposed to 2,4-D, 3-CB, 4-FB or 2,4,6-TCP during exponential growth on fructose as growth substrate, and total RNA was extracted for RT-PCR analysis. The pJP4encoded MAR genes ( $t f d F_{\mathrm{I}}$ and $\left.t f d F_{\mathrm{II}}\right)$ were clearly induced by compounds that produce chlorocatechols as central intermediates (3-CB and 2,4-D) (Fig. 2), in agreement with earlier reports (Laemmli et al., 2004; Leveau et al., 1999). Interestingly, 4-FB turnover, which generates 4-fluorocatechol as intermediate (Schlomann et al., 1990a), also induced $t f d F_{\mathrm{I}}$ and $t f d F_{\mathrm{II}}$. 2,4,6-TCP induced $t c p D$, and a slight induction of $t f d F_{\mathrm{I}}$ by $2,4,6-\mathrm{TCP}$ was also observed (Fig. 2), in accordance with an earlier report (Sánchez \& González, 2007). In contrast, hqoD and $h x q D$ showed no induction pattern in response to any haloaromatic compound tested (Fig. 2). Under our assay conditions, only $t f d F_{\text {I }}$ gene transcripts were detected in the absence of haloaromatic inducers (Fig. 2).

\section{Functional assays for chromosomally encoded MAR genes}

To assess the functionality of chromosomal MAR-encoding genes of $C$. necator JMP134, tcpD, $h x q D$ and $h q o D$ were cloned downstream of the arabinose-inducible promoter $\mathrm{P}_{\mathrm{BAD}}$ in $\mathrm{pBS} 1$ to generate $\mathrm{pBS} 1 t \mathrm{t} p D, \mathrm{pBS} 1 h x q D$ and pBS1hqoD, respectively, and transferred to $P$. putida

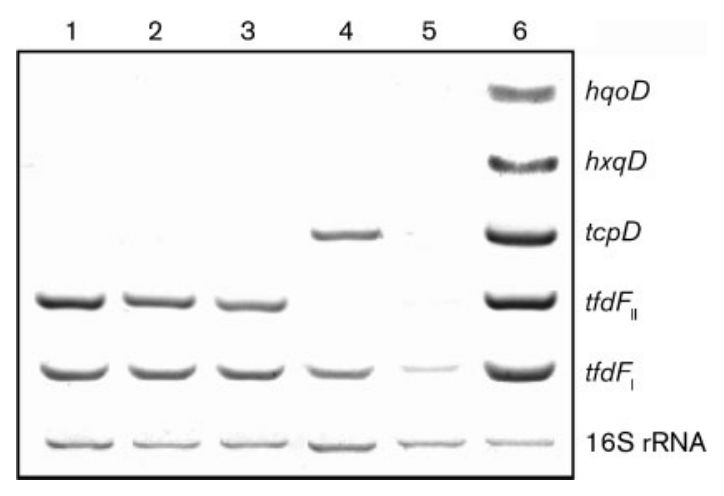

Fig. 2. RT-PCR analysis of MAR-encoding genes in $C$. necator JMP134 following exposure to 2,4-D (lane 1), 3-CB (2), 4-FB (3), $2,4,6$-TCP (4) or no inducer (5). Lane 6, PCR products obtained from C. necator JMP134 DNA. 
KT2442. The genome of this strain does not contain putative MAR-encoding genes (Matus et al., 2003), and no measurable MAR activity was detected in a $P$. putida cellfree extract (data not shown). Cell extracts of $P$. putida KT2442(pBS1tcpD) contained $5983 \pm 1322$ U MAR activity $\mathrm{g}^{-1}$, whereas $h q o D$ - or $h x q D$-expressing $P$. putida derivatives showed $1112 \pm 247$ and $332 \pm 128 \mathrm{U}$ MAR activity $\mathrm{g}^{-1}$, respectively. These values are similar to previously reported MAR activity levels in cell extracts of $C$. necator derivatives (Pérez-Pantoja et al., 2000; Plumeier et al., 2002).

The in vivo functionality of these chromosomal MARencoding genes was assessed in an engineered strain that allowed heterologous complementation for MAR function. B. phytofirmans PsJN (Sessitsch et al., 2005) grew on 2,4-D when harbouring an intact pJP4 plasmid (Table 3). However, strain PsJN supplied with a pJP4 derivative lacking both $t f d F_{\mathrm{I}}$ and $t f d F_{\mathrm{II}}\left(\mathrm{pJP} 4 \Delta t f d F_{\mathrm{I}} \Delta t f d F_{\mathrm{II}}\right)$ was not able to grow on 2,4-D (Table 3), in agreement with the absence of putative MAR-encoding genes in the genome of this bacterium. Therefore, introduction of a gene sequence encoding a functional MAR should allow growth of this bacterium on 2,4-D. The complementation of $B$. phytofirmans $\left(\mathrm{pJP} 4 \Delta t f d F_{\mathrm{I}} \Delta t f d F_{\mathrm{II}}\right)$ with pBS1tcpD, pBS1hxqD or pBS1hqoD plasmids completely restored the 2,4-Ddegrading phenotype (Table 3 ).

\section{Catabolic phenotype of mutants in MAR-encoding genes of C. necator JMP134}

In order to evaluate the contribution of MAR-encoding genes to haloaromatic compound catabolism in strain
JMP134, each MAR gene was mutated by insertional inactivation. The five C. necator JMP134 MAR mutants (Table 1) were tested for growth on haloaromatic substrates (Table 3 ). The $t f d F_{\mathrm{I}}$ mutant showed slightly slower growth on 2,4-D. However, a polar effect over $t f d B_{\mathrm{I}}$ (located downstream from $t f d F_{\mathrm{I}}$, Fig. $1 \mathrm{~b}$ ) seems to be responsible for the delay on growth, because complementation with a $t f d B_{\mathrm{I}}$-expressing plasmid completely restored efficient growth on 2,4-D (data not shown). The $t f d F_{\text {II }}$ mutant did not show significant effects on growth on any of these haloaromatic compounds. These results showed that pJP4 MAR-encoding genes are not essential for growth on haloaromatic compounds metabolized through chlorocatechols in C. necator JMP134, in accordance to an earlier report (Laemmli et al., 2004). The tcpD mutant showed a significant decrease in growth on 2,4,6-TCP, as reported previously (Sánchez \& González, 2007), but growth on this compound was not abolished. Finally, $h q o D$ and $h x q D$ mutants showed a behaviour similar to the wild-type strain on all haloaromatic compounds. In summary, the inactivation of single MAR-encoding genes in C. necator JMP134 did not abolish growth on any of these four haloaromatic compounds, indicating a functional redundancy of MAR-encoding genes.

To study if chromosomal MAR-encoding genes are able to supply the function of the pJP4-located MAR genes in the turnover of chlorocatechols, a $t f d F_{\mathrm{I}}-t f d F_{\mathrm{II}}$ double mutant of C. necator JMP134 was constructed. The $C$. necator JMP134(pJP4 $\left.4 t f d F_{\mathrm{I}} \Delta t f d F_{\text {II }}\right)$ strain still grew on all substrates tested, although severely retarded on 3-CB (Table 3), indicating that some or all the chromosomally encoded

Table 3. Growth of C. necator JMP134 mutant derivatives and B. phytofirmans PsJN engineered derivatives on haloaromatic compounds

++++ , Growth in less than 1 day; +++ , growth in $1-3$ days; ++ , growth in $3-5$ days; + , growth in $5-7$ days; - , no growth; NA, not applicable.

\begin{tabular}{|c|c|c|c|c|}
\hline \multirow[t]{2}{*}{ Strain } & \multicolumn{4}{|c|}{ Growth on (sole carbon and energy source) } \\
\hline & 2,4-D & 3-CB & 4-FB & $2,4,6-\mathrm{TCP}$ \\
\hline JMP134(pJP4) & ++++ & +++ & + & ++ \\
\hline $\mathrm{JMP} 134\left(\mathrm{pJP} 4 \Delta t f d F_{\mathrm{I}}\right)$ & +++ & +++ & + & ++ \\
\hline $\mathrm{JMP} 134\left(\mathrm{pJP} 4 \Delta t f d F_{\mathrm{II}}\right)$ & ++++ & +++ & + & ++ \\
\hline $\mathrm{JMP} 134 \Delta t c p D(\mathrm{pJP} 4)$ & ++++ & +++ & + & + \\
\hline JMP134shqoD(pJP4) & ++++ & +++ & + & ++ \\
\hline $\mathrm{JMP} 134 \Delta h x q D(\mathrm{pJP} 4)$ & ++++ & +++ & + & ++ \\
\hline $\mathrm{JMP} 134\left(\mathrm{pJP} 4 \Delta t f d F_{\mathrm{I}} \Delta t f d F_{\mathrm{II}}\right)$ & +++ & + & + & ++ \\
\hline $\mathrm{JMP} 134 \Delta t c p D\left(\mathrm{pJP} 4 \Delta t f d F_{\mathrm{I}} \Delta t f d F_{\mathrm{II}}\right)$ & +++ & + & + & + \\
\hline $\mathrm{JMP} 134 \Delta h x q D\left(\mathrm{pJP} 4 \Delta t f d F_{\mathrm{I}} \Delta t f d F_{\mathrm{II}}\right)$ & ++ & + & + & ++ \\
\hline $\mathrm{JMP} 134 \Delta h q o D\left(\mathrm{pJP} 4 \Delta t f d F_{\mathrm{I}} \Delta t f d F_{\mathrm{II}}\right)$ & +++ & + & + & ++ \\
\hline PsjN & - & NA & NA & $\mathrm{NA}$ \\
\hline PsJN(pJP4) & +++ & NA & NA & NA \\
\hline $\operatorname{PsJN}\left(\mathrm{pJP} 4 \Delta t f d F_{\mathrm{I}} \Delta t f d F_{\mathrm{II}}\right)$ & - & NA & NA & NA \\
\hline $\operatorname{PsJN}\left(\mathrm{pJP} 4 \Delta t f d F_{\mathrm{I}} \Delta t f d F_{\mathrm{II}}\right)(\mathrm{pBS} 1 t c p D)$ & +++ & NA & NA & NA \\
\hline $\operatorname{PsJN}\left(\mathrm{pJP} 4 \Delta t f d F_{\mathrm{I}} \Delta t f d F_{\mathrm{II}}\right)(\mathrm{pBS} 1 h q o D)$ & +++ & NA & NA & NA \\
\hline $\operatorname{PsJN}\left(\mathrm{pJP} 4 \Delta t f d F_{\mathrm{I}} \Delta t f d F_{\mathrm{II}}\right)(\mathrm{pBS} 1 h x q D)$ & +++ & NA & NA & NA \\
\hline
\end{tabular}


MAR genes are able to replace the mutated pJP4-encoded genes. Triple mutants showed essentially the same growth pattern of C. necator JMP134(pJP4 $\left.\Delta t f d F_{\mathrm{I}} \Delta t f d F_{\mathrm{II}}\right)$ on 2,4-D, 3 -CB or 4-FB (Table 3), except for slower growth of $C$. necator JMP134 $h h x q D\left(\mathrm{pJP} 4 \Delta t f d F_{\mathrm{I}} \Delta t f d F_{\mathrm{II}}\right)$ on $2,4-\mathrm{D}$. On the other hand, C. necator JMP $134 \Delta t c p D\left(\mathrm{pJP} 4 \Delta t f d F_{\mathrm{I}} \Delta t f d F_{\mathrm{II}}\right)$ showed a similar impaired growth on 2,4,6-TCP as $C$. necator JMP134 $\Delta t c p D$. These results indicate that the other chromosomal MAR functions are replacing the inactivated genes, and that only two out of the five MAR-encoding genes are enough to support growth on the four haloaromatic compounds tested.

\section{Induction of MAR activity in MAR-encoding gene mutants of C. necator JMP134}

To evaluate the role of MAR-encoding genes in the induction of MAR activity by 2,4-D or 2,4,6-TCP, MAR activity levels were measured in C. necator JMP134 mutant derivatives (Fig. 3). The induction of MAR activity by 2,4-D or 2,4,6-TCP in the wild-type strain (Fig. 3) was as reported in earlier studies (Padilla et al., 2000; Pieper et al., 1988). The induction of MAR activity by 2,4-D was completely abolished in C. necator JMP134(pJP4 $\Delta t f d F_{\mathrm{I}} \Delta t f d F_{\mathrm{II}}$ ) (Fig. 3), indicating that chromosomally encoded MAR genes are not turned on in response to this compound, as indicated by RT-PCR analysis (Fig. 2). On the other hand, the induction of MAR activity by 2,4,6-TCP was completely abolished in $C$. necator JMP134 $t c p D$ (Fig. 3), confirming the main (but not essential) role of $t c p D$ in turnover of this compound (Table 3). On the other hand, the basal MAR activity under non-induced conditions was not abolished in any mutant derivative. However, a significant decrease of basal MAR activity levels was observed in C. necator

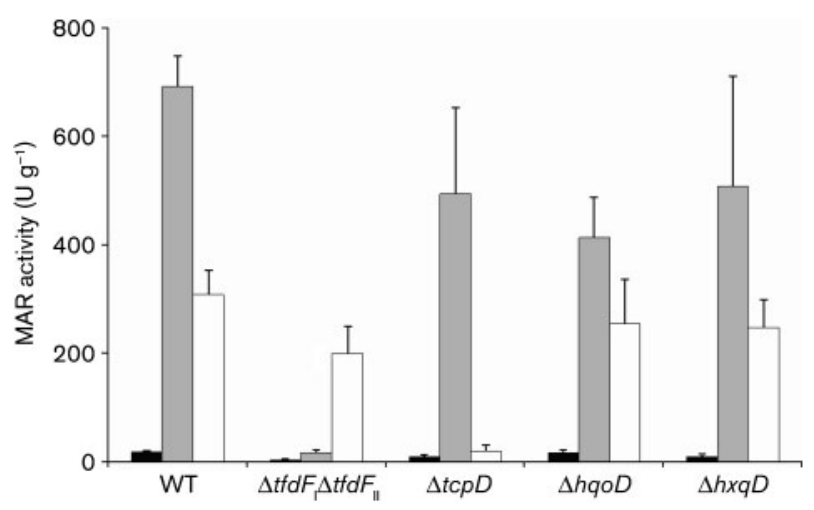

Fig. 3. Summed MAR activity levels in cell extracts of derivatives of C. necator JMP134 grown in the absence of haloaromatic compounds (black bars ), the presence of 2,4-D (grey), or the presence of 2,4,6-TCP (white bars). Values are the means of three independent determinations. Vertical bars represent SD from the mean.
JMP134(pJP4 $\Delta t f d F_{\mathrm{I}} \Delta t f d F_{\text {II }}$ ) (Fig. 3). This result is also in agreement with the RT-PCR detection of $t f d F_{\mathrm{I}}$ transcripts in the absence of haloaromatic inducers (Fig. 2).

\section{DISCUSSION}

Genetic redundancy means that two or more genes are performing the same function in one organism and that inactivation of one of these genes has little or no effect on the phenotype of the organism. Despite the fact that redundant genes are likely to be eliminated by selective pressure, an analysis of 106 bacterial genomes has revealed that a significant number of apparent genetic redundancies have been maintained in individual genomes (Gevers et al., 2004). However, it should be mentioned that functional support for these apparent genetic redundancies is required for the redundancy to be considered genuine.

In this work we clearly showed that MAR genes of $C$. necator JMP134 constitute a striking example of genuine genetic redundancy. This well-known bacterial model for microbial degradation of aromatic compounds possesses five functional genes encoding MAR, a catabolic function playing a fundamental role in channelling intermediates into the Krebs cycle and, therefore, allowing bacteria to use aromatic compounds as sole carbon and energy sources.

The two plasmid-encoded MAR in C. necator JMP134 have been extensively studied (Kasberg et al., 1995; Muller et al., 1996; Seibert et al., 1993; Vollmer et al., 1993). Both pJP4encoded MAR genes $\left(t f d F_{\mathrm{I}}\right.$ and $\left.t f d F_{\mathrm{II}}\right)$ are functional and contribute to catabolism of chlorocatechols (Plumeier et al., 2002). However, $t f d F_{\mathrm{I}}$ and $t f d F_{\mathrm{II}}$ are not essential for degradation of chloroaromatic compounds and are, therefore, redundant (Laemmli et al., 2004). Previous work has suggested the presence of chromosomally encoded MAR in C. necator, since MAR activity was reported in cell extracts of C. necator JMP222 - a pJP4-cured derivative grown on 4-FB (Plumeier et al., 2002; Schlomann et al., 1990a), indicating that at least one chromosomally encoded MAR gene can replace the function of pJP4encoded MAR genes. One candidate to fulfil this role was $t c p D$ involved in the degradation of 2,4,6-TCP (Sánchez \& González, 2007). However, this MAR activity had not been further evaluated. Two other putative MAR-encoding genes, $h q o D$ and $h x q D$, have been proposed to be involved in chlorohydroquinone and hydroxyquinol catabolism, respectively, since they are clustered with putative ringcleavage dioxygenase-encoding genes (Pérez-Pantoja et al., 2008). In contrast to $t c p D$ and the two pJP4 encoded MAR genes, where specific aromatic compounds (2,4,6-TCP, 2,4D) can be used in growth tests, chlorohydroquinone and hydroxyquinol are too toxic to be assayed as growth substrates in C. necator JMP134 (data not shown). Unfortunately, the putative compounds that produce chlorohydroquinone and hydroxyquinol as intermediates in C. necator are unknown and the corresponding growth tests cannot be carried out. 


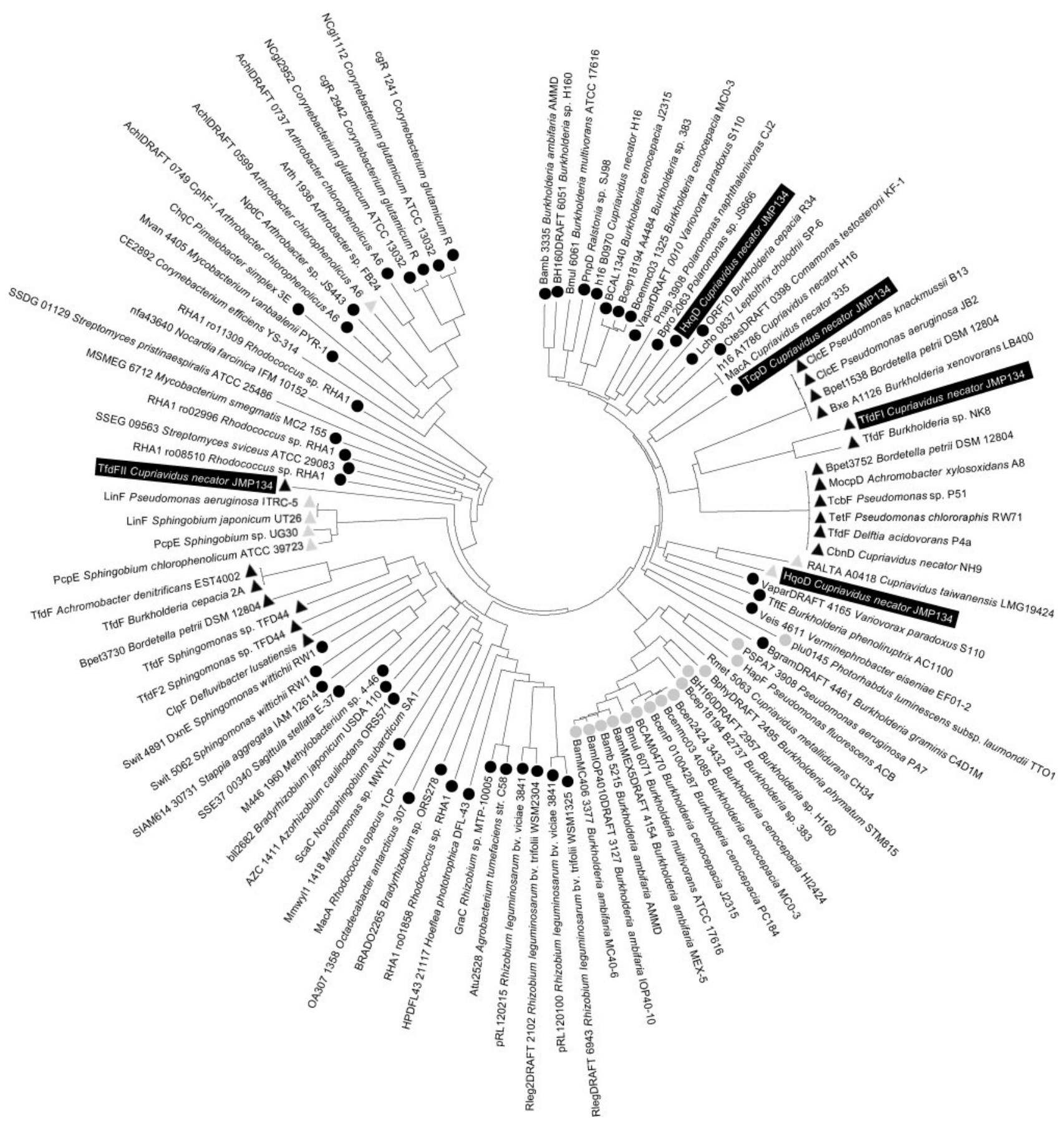

Fig. 4. Dendrogram showing the relatedness of MAR gene products. The dendrogram was obtained by the neighbour-joining method using MEGA 4.0 based on sequence alignments calculated by CLUSTAL W using the default options. Sequences of deduced proteins encoded in the genome of C. necator JMP134 are highlighted in black. The positional clustering of MARencoding genes with genes putatively encoding chlorocatechol 1,2-dioxygenase (black triangles), (chloro)hydroxyquinol 1,2dioxygenase (black circles), chlorohydroquinone 1,2-dioxygenase (grey triangles) or hydroquinone 1,2-dioxygenase (grey circles) is shown. Sequences with $>30 \%$ amino acid identity to the $t f d F_{1}$ gene product were selected from the NCBI database.

In this work, we studied the role of chromosomal MARencoding genes in the catabolism of haloaromatics. By using both in vivo and in vitro approaches, it has been clearly shown that the three chromosomally encoded MAR are functional and provide the required MAR activity for 2,4-D catabolism in the heterologous system of $B$. phytofirmans PsJN. In addition, multiple mutation analysis supported the redundancy of MAR genes, since only two 
genes are enough to perform this function in haloaromatic catabolism in C. necator JMP134. However, the induction profile of the five MAR genes showed some specificity. As expected, $t f d F_{\mathrm{I}}$ and $t f d F_{\mathrm{II}}$ were induced by $2,4-\mathrm{D}$ and $3-\mathrm{CB}$, which generate the corresponding chloromuconates, inducers of the $t f d$ operons (Filer \& Harker, 1997). In the same way, 4-FB, which produces the analogue 3-fluoro-cis,cismuconate (Schlomann et al., 1990b), also induces $t f d F_{\mathrm{I}}$ and $t f d F_{\mathrm{II}}$, indicating that $t f d$ genes probably contribute to 4 -FB catabolism. However, the presence of $t f d$ genes is not essential, since a pJP4-lacking derivative, C. necator JMP222, is still able to grow on this substrate (Schlomann et al., 1990a). hqoD and hxqD did not show induction by any of the haloaromatic compounds tested, suggesting a role in catabolism of as yet unidentified aromatic compounds, probably channelled to chlorohydroquinone and/or hydroxyquinol as ring-cleavage intermediates. The results of MAR activity level tests in mutant derivatives showed that in the absence of the genes induced by $2,4-\mathrm{D}$ and $2,4,6-\mathrm{TCP}-t f d F_{\mathrm{I}} / t f d F_{\mathrm{II}}$ and $t c p D$, respectively - no induction of the other MAR-encoding genes was observed; this suggests that these genes are not responsive to accumulation of MA or 2-CMA. However, the low background MAR activity level found in these mutant derivatives is enough to support growth on 2,4-D and 2,4,6-TCP.

The findings reported here raise the question of why such genetic redundancy is maintained in the genome of $C$. necator JMP134. We hypothesized that the reason to keep the five MAR-encoding genes is to avoid the intracellular accumulation of MA during haloaromatic catabolism. MA is unstable and at neutral $\mathrm{pH}$ is spontaneously decarboxylated to cis-acetylacrylate, a dead-end metabolite (Schlomann et al., 1990b). It is interesting to note that each MAR gene in the genome of strain JMP134 is clustered with at least one gene putatively encoding a ringcleavage dioxygenase producing $\mathrm{MA}$ as a downstream metabolite: chlorocatechol 1,2-dioxygenases ( $\mathrm{TfdC}_{\mathrm{I}} /$ $\mathrm{TfdC}_{\mathrm{II}}$ ); (chloro)hydroxyquinol 1,2-dioxygenases (TcpC/ $\mathrm{HxqC}$ ) and chlorohydroquinone 1,2-dioxygenase (HqoE) (Fig. 1b) (Pérez-Pantoja et al., 2008). This positional clustering suggests that MAR genes are co-induced with the genes encoding the corresponding upstream step in the pathways, avoiding the possible accumulation of MA.

A dendrogram of MAR gene products, including sequences from complete genomes is shown in Fig. 4. An analysis of the gene sequences flanking MAR-encoding genes included in this dendrogram indicates that the vast majority of MAR genes are associated with genes putatively encoding ring-cleavage dioxygenases that generate MA, as found in strain JMP134. The clustering of MAR gene products belonging to $C$. necator JMP134 indicates that HxqD, putatively involved in hydroxyquinol catabolism, and $\mathrm{TfdF}_{\mathrm{I}}$, involved in chlorocatechol catabolism, grouped with several other MAR involved in similar pathways. On the contrary, TcpD and HqoD grouped in small branches with no clear pathway-associated profile, probably indicating that recruitment of these genes in their respective gene clusters is more recent. Finally, it should be noted that $\mathrm{TfdF}_{\mathrm{II}}$ is not closely related to any other MAR, indicating a completely different evolutionary origin.

It is remarkable that apparent MAR gene redundancy has been found in the genomes of 17 strains included in the dendrogram in Fig. 4, and that the number of MAR genes in these genomes is roughly equal to the number of genes putatively encoding ring-cleavage dioxygenases that generate MA. These observations support the idea that MAR gene redundancy is widespread in bacteria having more than one pathway generating MA as a downstream metabolite.

\section{ACKNOWLEDGEMENTS}

This work has been funded by the FONDECYT grant 1070343 and the 'Millennium Nucleus in Microbial Ecology and Environmental Microbiology and Biotechnology' grant P/04-007-F. This study is also part of the research program FONDAP 1501-0001 funded by CONICYT to the Center for Advanced Studies in Ecology \& Biodiversity Program 7. Additional support from grant PBCT RED12 is acknowledged. D. P.-P. is a CONICYT-DAAD PhD fellow. R. A. D. and M.A.S. are CONICYT PhD fellows. We thank Matthew P. DeLisa (School of Chemical and Biomolecular Engineering, Cornell University, Ithaca, NY) for providing pBS1, and Michael L. Kahn (Institute of Biological Chemistry, Washington State University, Pullman, WA) for providing pBH474. We are grateful to Dietmar H. Pieper for critical reading of the manuscript.

\section{REFERENCES}

Armengaud, J., Timmis, K. N. \& Wittich, R. M. (1999). A functional 4hydroxysalicylate/hydroxyquinol degradative pathway gene cluster is linked to the initial dibenzo-p-dioxin pathway genes in Sphingomonas sp. strain RW1. J Bacteriol 181, 3452-3461.

Bradford, M. M. (1976). A rapid and sensitive method for the quantitation of microgram quantities of protein utilizing the principle of protein-dye binding. Anal Biochem 72, 248-254.

Bronstein, P. A., Marrichi, M., Cartinhour, S., Schneider, D. J. \& DeLisa, M. P. (2005). Identification of a twin-arginine translocation system in Pseudomonas syringae pv. tomato DC3000 and its contribution to pathogenicity and fitness. J Bacteriol 187, 8450-8461.

Clément, P., Springael, D. \& González, B. (2000). Deletions of $m o b$ and tra pJP4 transfer functions after mating of Ralstonia eutropha JMP134 (pJP4) with Escherichia coli harboring $\mathrm{F}^{\prime}:$ :Tn10. Can J Microbiol 46, 485-489.

Datsenko, K. A. \& Wanner, B. L. (2000). One-step inactivation of chromosomal genes in Escherichia coli K-12 using PCR products. Proc Natl Acad Sci U S A 97, 6640-6645.

Daubaras, D. L., Saido, K. \& Chakrabarty, A. M. (1996). Purification of hydroxyquinol 1,2-dioxygenase and maleylacetate reductase: the lower pathway of 2,4,5-trichlorophenoxyacetic acid metabolism by Burkholderia cepacia AC1100. Appl Environ Microbiol 62, 4276-4279.

Dorn, E., Hellwig, M., Reineke, W. \& Knackmuss, H.-J. (1974). Isolation and characterization of a 3-chlorobenzoate degrading pseudomonad. Arch Microbiol 99, 61-70.

Endo, R., Kamakura, M., Miyauchi, K., Fukuda, M., Ohtsubo, Y., Tsuda, M. \& Nagata, Y. (2005). Identification and characterization of 
genes involved in the downstream degradation pathway of $\gamma$ hexachlorocyclohexane in Sphingomonas paucimobilis UT26. J Bacteriol 187, 847-853.

Filer, K. \& Harker, A. R. (1997). Identification of the inducing agent of the 2,4-dichlorophenoxyacetic acid pathway encoded by plasmid pJP4. Appl Environ Microbiol 63, 317-320.

Gaal, A. B. \& Neujahr, H. Y. (1980). Maleylacetate reductase from Trichosporon cutaneum. Biochem J 185, 783-786.

Gevers, D., Vandepoele, K., Simillon, C. \& Van de Peer, Y. (2004). Gene duplication and biased functional retention of paralogs in bacterial genomes. Trends Microbiol 12, 148-154.

House, B. L., Mortimer, M. W. \& Kahn, M. L. (2004). New recombination methods for Sinorhizobium meliloti genetics. Appl Environ Microbiol 70, 2806-2815.

Huang, Y., Zhao, K. X., Shen, X. H., Chaudhry, M. T., Jiang, C. Y. \& Liu, S. J. (2006). Genetic characterization of the resorcinol catabolic pathway in Corynebacterium glutamicum. Appl Environ Microbiol 72, 7238-7245.

Jones, K. H., Trudgill, P. W. \& Hopper, D. J. (1995). Evidence of two pathways for the metabolism of phenol by Aspergillus fumigatus. Arch Microbiol 163, 176-181.

Kasberg, T., Daubaras, D. L., Chakrabarty, A. M., Kinzelt, D. \& Reineke, W. (1995). Evidence that operons $t c b$, $t f d$, and $c l c$ encode maleylacetate reductase, the fourth enzyme of the modified ortho pathway. J Bacteriol 177, 3885-3889.

Kaschabek, S. R. \& Reineke, W. (1992). Maleylacetate reductase of Pseudomonas sp. strain B13: dechlorination of chloromaleylacetates, metabolites in the degradation of chloroaromatic compounds. Arch Microbiol 158, 412-417.

Kaschabek, S. R. \& Reineke, W. (1995). Maleylacetate reductase of Pseudomonas sp. strain B13: specificity of substrate conversion and halide elimination. J Bacteriol 177, 320-325.

Laemmli, C. M., Leveau, J. H., Zehnder, A. J. \& van der Meer, J. R. (2000). Characterization of a second $t f d$ gene cluster for chlorophenol and chlorocatechol metabolism on plasmid pJP4 in Ralstonia eutropha JMP134(pJP4). J Bacteriol 182, 4165-4172.

Laemmli, C., Werlen, C. \& van der Meer, J. R. (2004). Mutation analysis of the different $t f d$ genes for degradation of chloroaromatic compounds in Ralstonia eutropha JMP134. Arch Microbiol 181, $112-121$.

Ledger, T., Pieper, D. H., Pérez-Pantoja, D. \& González, B. (2002). Novel insights into the interplay between peripheral reactions encoded by $x y l$ genes and the chlorocatechol pathway encoded by $t f d$ genes for the degradation of chlorobenzoates by Ralstonia eutropha JMP134. Microbiology 148, 3431-3440.

Leveau, J. H., Konig, F., Fuchslin, H., Werlen, C. \& van der Meer, J. R. (1999). Dynamics of multigene expression during catabolic adaptation of Ralstonia eutropha JMP134 (pJP4) to the herbicide 2, 4-dichlorophenoxyacetate. Mol Microbiol 33, 396-406.

Matus, V., Sánchez, M. A., Martínez, M. \& González, B. (2003). Efficient degradation of 2,4,6-trichlorophenol requires a set of catabolic genes related to tcp genes from Ralstonia eutropha JMP134(pJP4). Appl Environ Microbiol 69, 7108-7115.

Moonen, M. J., Kamerbeek, N. M., Westphal, A. H., Boeren, S. A., Janssen, D. B., Fraaije, M. W. \& van Berkel, W. J. (2008). Elucidation of the 4-hydroxyacetophenone catabolic pathway in Pseudomonas fluorescens ACB. J Bacteriol 190, 5190-5198.

Muller, D., Schlomann, M. \& Reineke, W. (1996). Maleylacetate reductases in chloroaromatic-degrading bacteria using the modified ortho pathway: comparison of catalytic properties. J Bacteriol 178, 298-300.
Nikodem, P., Hecht, V., Schlomann, M. \& Pieper, D. H. (2003). New bacterial pathway for 4- and 5-chlorosalicylate degradation via 4chlorocatechol and maleylacetate in Pseudomonas sp. strain MT1. J Bacteriol 185, 6790-6800.

Padilla, L., Matus, V., Zenteno, P. \& González, B. (2000). Degradation of 2,4,6-trichlorophenol via chlorohydroxyquinol in Ralstonia eutropha JMP134 and JMP222. J Basic Microbiol 40, 243-249.

Patel, T. R., Hameed, N. \& Armstrong, S. (1992). Metabolism of gallate in Penicillium simplicissimum. J Basic Microbiol 32, 233-240.

Pérez-Pantoja, D., Guzmán, L., Manzano, M., Pieper, D. H. \& González, B. (2000). Role of $t f d C(\mathrm{I}) D(\mathrm{I}) E(\mathrm{I}) F(\mathrm{I})$ and $t f d D($ II) $C(\mathrm{II}) E(\mathrm{II}) F(\mathrm{II})$ gene modules in catabolism of 3-chlorobenzoate by Ralstonia eutropha JMP134(pJP4). Appl Environ Microbiol 66, 1602-1608.

Pérez-Pantoja, D., Ledger, T., Pieper, D. H. \& González, B. (2003). Efficient turnover of chlorocatechols is essential for growth of Ralstonia eutropha JMP134(pJP4) in 3-chlorobenzoic acid. J Bacteriol 185, 1534-1542.

Pérez-Pantoja, D., De la Iglesia, R., Pieper, D. H. \& González, B. (2008). Metabolic reconstruction of aromatic compounds degradation from the genome of the amazing pollutant-degrading bacterium Cupriavidus necator JMP134. FEMS Microbiol Rev 32, 736-794.

Perry, L. L. \& Zylstra, G. J. (2007). Cloning of a gene cluster involved in the catabolism of $p$-nitrophenol by Arthrobacter sp. strain JS443 and characterization of the $p$-nitrophenol monooxygenase. J Bacteriol 189, 7563-7572.

Pieper, D. H., Reineke, W., Engesser, K. H. \& Knackmuss, H.-J. (1988). Metabolism of 2,4-dichlorophenoxyacetic acid, 4-chloro-2methylphenoxyacetic acid and 2-methylphenoxyacetic acid by Alcaligenes eutrophus JMP 134. Arch Microbiol 150, 95-102.

Plumeier, I., Pérez-Pantoja, D., Heim, S., González, B. \& Pieper, D. H. (2002). Importance of different $t f d$ genes for degradation of chloroaromatics by Ralstonia eutropha JMP134. J Bacteriol 184, 40544064.

Sánchez, M. A. \& González, B. (2007). Genetic characterization of 2,4,6-trichlorophenol degradation in Cupriavidus necator JMP134. Appl Environ Microbiol 73, 2769-2776.

Schlomann, M., Fischer, P., Schmidt, E. \& Knackmuss, H.-J. (1990a). Enzymatic formation, stability, and spontaneous reactions of 4fluoromuconolactone, a metabolite of the bacterial degradation of 4-fluorobenzoate. J Bacteriol 172, 5119-5129.

Schlomann, M., Schmidt, E. \& Knackmuss, H.-J. (1990b). Different types of dienelactone hydrolase in 4-fluorobenzoate-utilizing bacteria. J Bacteriol 172, 5112-5118.

Seibert, V., Stadler-Fritzsche, K. \& Schlomann, M. (1993). Purification and characterization of maleylacetate reductase from Alcaligenes eutrophus JMP134(pJP4). J Bacteriol 175, 6745-6754.

Seibert, V., Kourbatova, E. M., Golovleva, L. A. \& Schlomann, M. (1998). Characterization of the maleylacetate reductase MacA of Rhodococcus opacus 1CP and evidence for the presence of an isofunctional enzyme. J Bacteriol 180, 3503-3508.

Seibert, V., Thiel, M., Hinner, I. S. \& Schlomann, M. (2004). Characterization of a gene cluster encoding the maleylacetate reductase from Ralstonia eutropha 335T, an enzyme recruited for growth with 4-fluorobenzoate. Microbiology 150, 463-472.

Sessitsch, A., Coenye, T., Sturz, A. V., Vandamme, E., Barka, P. A., Salles, J. F., van Elsas, J. D., Faure, D., Reiter, B. \& other authors (2005). Burkholderia phytofirmans sp. nov., a novel plant-associated bacterium with plant-beneficial properties. Int J Syst Evol Microbiol 55, 1187-1192.

Sparnins, V. L., Burbee, D. G. \& Dagley, S. (1979). Catabolism of L-tyrosine in Trichosporon cutaneum. J Bacteriol 138, 425-430. 
Travkin, V. M., Linko, E. V. \& Golovleva, L. A. (1999). Purification and characterization of maleylacetate reductase from Nocardioides simplex 3E utilizing phenoxyalcanoic herbicides 2,4-D and 2,4,5-T. Biochemistry (Mosc) 64, 625-630.

Trefault, N., De la Iglesia, R., Molina, A. M., Manzano, M., Ledger, T., Pérez-Pantoja, D., Sánchez, M. A., Stuardo, M. \& González, B. (2004). Genetic organization of the catabolic plasmid pJP4 from Ralstonia eutropha JMP134 (pJP4) reveals mechanisms of adaptation to chloroaromatic pollutants and evolution of specialized chloroaromatic degradation pathways. Environ Microbiol 6, 655-668.
Vollmer, M. D., Stadler-Fritzsche, K. \& Schlomann, M. (1993). Conversion of 2-chloromaleylacetate in Alcaligenes eutrophus JMP134. Arch Microbiol 159, 182-188.

Yoshida, M., Oikawa, T., Obata, H., Abe, K., Mihara, H. \& Esaki, N. (2007). Biochemical and genetic analysis of the $\gamma$-resorcylate $(2,6-$ dihydroxybenzoate) catabolic pathway in Rhizobium sp. strain MTP10005: identification and functional analysis of its gene cluster. J Bacteriol 189, 1573-1581.

Edited by: D. J. Arp 